\title{
Effect of frying on physicochemical properties of sesame and soybean oil blend
}

\section{Meenakshi Garg}

Department of Food Technology, Bhaskaracharya College of Applied Sciences, University of Delhi, New Delhi, India

\section{Surabhi Wason}

Department of Food Technology, Bhaskaracharya College of Applied Sciences, University of Delhi, New Delhi, India

\section{Prem Lata Meena*}

Department of Polymer Sciences, Bhaskaracharya College of Applied Sciences, University of Delhi, New Delhi, India

\section{Rajni Chopra}

Department of Food Science and Technology, National Institute of Food Technology Entrepreneurship and Management, Sonipat (Haryana), India

\section{Susmita Dey Sadhu}

Department of Polymer Sciences, Bhaskaracharya College of Applied Sciences, University of Delhi, New Delhi, India

\section{Akriti Dhyani}

Department of Foods and Nutrition, Institute of Home Economics, University of Delhi, New Delhi, India

${ }^{*}$ Corresponding author. Email: premlatameena23@gmail.com

\section{How to Cite}

Garg, M. et al. (2021). Effect of frying on physicochemical properties of sesame and soybean oil blend. Journal of Applied and Natural Science, 13(3), 820 - 829. https://doi.org/10.31018/jans.v13i3.2744

\begin{abstract}
Most common cooking oil, such as soybean oil, can not be used for high-temperature applications, as they are highly susceptible to oxidation. Sesame seed oil rich in natural antioxidants provides high oxidative stability. Therefore, blending sesame oil with soybean oil offer improved oxidative stability. This study aims to determine the effect of frying on the physicochemical properties of sesame and soyabean oil blend. Soybean oil (SO) was blended with sesame seed oil (SSO) in the ratio of A40:60, B60:40 and C-50:50 so as to enhance its market acceptability. The changes occurring in soybean and sesame seed oil blend during repeated frying cycles were monitored. The parameters assessed were: Refractive index, specific gravity, viscosity, saponification value, free fatty acid (FFA), peroxide value, and acid value. Fresh and fried oil blends were also characterised by Fourier Transform Infrared Spectroscopy (FTIR). No significant changes were observed for refractive index and specific gravity values in oil blends. Viscosity of blend $B$ blend was the least, making it desirable for cooking purposes. However, FFA, acid value and peroxide value increased after each frying cycle. The increment of FFA and AV was found low for blend A ( $10 \%$ and $10 \%$,$) than blend B(27 \%, 13 \%)$ and blend $C(13 \%, 13 \%)$. The peroxide value of all samples was within the acceptable range. The results of the present study definitely indicated that blending sesame oil with soybean oil could produce an oil blend which is economically feasible and provide desirable physicochemical properties for cooking purposes.
\end{abstract}

Keywords: Blending, Density, Free fatty acid, Oil blends, Sesame seed oil, Soybean oil

\section{INTRODUCTION}

In food preparation, the most common ingredient is oil. Soybean oil is widely used in various cooking processes, most commonly being Deep fat frying. In deep-fat frying, food is immersed in hot oil and is in contact with oil, air and food at a high temperature of 150 to $190^{\circ} \mathrm{C}$.
It gives food a desirable flavour, colour and crispy texture, which is enjoyed by consumers (Boskou et al., 2006). Various reactions occur during deep fat frying, resulting in the production of many compounds that affect the oil's sensory, functional, and nutritional characteristics (Alireza et al., 2010).

These reactions vary widely depending on variety of 
factors. The physical properties of edible oils, such as viscosity and heat transfer, could be the primary factors that influence variation in fried food quality. Other factors could be quality of oil, food material, duration of frying, temperature of frying and frying conditions. Many studies reveal that consumers prefer oils for food preparation, with lower viscosity, density, and low melting point values. But higher unsaturation in such oils increases the chances of rancidity. Moreover, the rancidity of oils also depends on the process of storage, period and temperature (Aidos et al., 2002; Li et al., 2014; Sankar et al., 2003).

The fatty acid composition of Soybean oil (SBO) has been extensively investigated. Large amounts of linoleic and linolenic acids are found in SBO, compared with those in other vegetable oils. Although this fact is considered nutritionally favourable, the high content of polyunsaturated fatty acids (PUFA)makes it highly susceptible to oxidation of oils leading to off flavours development in Soybean oil. Thus, it affects the shelf life of a product.

Lipid oxidation has harmful effects on both food quality and human health. Then efforts must be made to minimize oxidation and improve oxidative stability of lipid products (Man and Tan, 2002). Over the years, many studies have been conducted to investigate the effects of frying on the physicochemical properties of different oil blends. According to a study, when soybean oil was blended with other unconventional oil (Humilis seed oil), it showed a significant effect on colour and oxidative stability during frying (Mokbli et al., 2018).

Sesame seed (Sesamum indicum L.) is one of the world's most important and oldest oilseed crops with a high-level content of antioxidant known to human health. It has a unique and pleasant flavour which is highly valued (Latif and Anwar, 2011). It forms an important source of edible oil. Although it contains approximately $85 \%$ unsaturated fatty acids, oxidative stability of sesame oil is superior among other vegetable oils (Abou-Gharbia et al., 2000). Because of this, sesame oil is stable and when mixed with other oils, actually increases the stability of the blend (Farhoosh and Kenari, 2009). SSO is highly resistant to oxidation and displays several medicinal effects. Sesame seed oil contains a number of antioxidants such as sesamin, sesamolin and sesamol which provides stability to the oil. Thus, it has a long shelf life and can be used to blend with less stable vegetable oils to enhance their stability (Rangkadilok et al., 2010). It also contributes the pleasant nutty flavour and linoleic acid content to the oil blends (Kochhar, 2002).

Blending of oils is also done to offer protective advantage against oxidation due to the presence of specific ingredients in the oil so that oil can be used couple of times before disposing it off (Toliwal et al.,2005). According to many studies conducted on blending of oils, bended oils are gaining popularity worldwide due to benefits such as improved thermal stability, oxidative stability, nutritional benefits and an ability to offer the desired properties (Pandurangan et al., 2014; Hashempour-Baltork et al., 2016; Dhyani et al., 2018 ). Also, they are considered cheaper alternatives or substitutes to pure vegetable oils. The aim of this work is to analyse the changes in physico-chemical properties of soybean oil when blended with sesame seed oil in different mixing ratio.

\section{MATERIALS AND METHODS}

The vegetable oil such as soybean oil (brand name fortune) and sesame seed oil (brand name- amazon) were purchased from INA market, New Delhi, India.

\section{Preparation of blends}

Three blends of soybean oil and sesame seed oil were prepared using a mechanical stirrer at $180 \mathrm{rpm}$ for $15 \mathrm{~min}$ (Kumar et al. 2009). These blends were prepared in the ratio of 40:60, 60:40 and 50:50. These three blends named as:

Sample $A=40 \%$ Soyabean oil \& $60 \%$ Sesame oil Sample $B=60 \%$ Soyabean oil \& $40 \%$ Sesame oil Sample C $=50 \%$ Soyabean oil \& $50 \%$ Sesame oil

\section{Frying cycle}

Properties of the oil blends were tested using the frying cycle method given by Debnath et al. (2009) with slight modification. Heating and frying were done under controlled conditions using a wok. Four batches of frying (each $2 \mathrm{~min}$ ) were conducted in a day without any time lag. This exercise was repeated for 3 consecutive days. For each frying experiment, $50 \mathrm{~g}$ of frozen commercially available French fries (McCain) were taken for each batch. After each cycle, the flame was put off and heated oil was allowed to cool to ambient temperature $\left(25 \pm 1{ }^{\circ} \mathrm{C}\right)$. The sample was drawn every day and stored in a brown bottle in the refrigerator for further analysis. The frying samples were named as:

FA1: first day of frying of sample $A$

FA2: second day of frying of sample $A$

FA3: third day of frying of sample $A$

FB1: first day of frying of sample $B$

FB2: second day of frying of sample $B$

FB3: third day of frying of sample $B$

FC1: first day of frying of sample $C$

FC2: second day of frying of sample $C$

FC3: third day of frying of sample $\mathrm{C}$

\section{Refractive index}

Abbe refractometer was used for the determination of refractive indices of oil and fat sample. Temperature of the refractometer was maintained at $40 \pm 0.1^{\circ} \mathrm{C}$ using a thermostatically controlled water bath. Refractive indi- 
ces were determined following the procedures given by Cocks and van Rede (1997).

\begin{abstract}
Viscosity
Viscosity of oil is a measure of the oil's resistance to shear. The viscosity of the blended oil was determined using Brookfield viscometer at constant temperature and shear rate. Measurement was taken at various shear rates using the method given by AOAC (2000).
\end{abstract}

\section{Specific gravity}

The specific gravity of an oil is the ratio of the weight of a given volume of the oil in air at a define temperature to that of the weight of the same volume of water at the same temperature (AOAC, 2000). For determining Specific gravity, a Pycnometer, i.e., specific gravity bottle, was used. The pycnometer was first cleaned, dried and then weighed. Water, at $20^{\circ} \mathrm{C}$ was filled into the pycnometer and weighed again. Then, it was emptied, cleaned, dried and filled with oil and finally weighed. The value was calculated using the equation:

Specific gravity of oil $=$ Weight of oil $/$ Weight of water at $20^{\circ} \mathrm{C}$ Eq.1

\section{Acid value}

The acid values represent the degradation of the oil quality resulting from the hydrolysis of triacylglycerol as well as further decomposition of hydroperoxides. The vegetable oil blends were prepared in 40: 60, $60: 40$ and 50:50 proportions and were also used for frying three times. The acid value was determined following the AOCS (2000) method no. Cd 5a-40. According to this method, $5 \mathrm{gm}$ oil sample is weighed and added 50 $\mathrm{ml}$ neutral alcohol in a flask. The flask was then heated for 30 minutes on a water bath and cooled till room temperature is attained. After that, few drops of phenolphthalein indicator was added and titrated with the standard $\mathrm{N} / 10 \mathrm{KOH}$ solution until a faint permanent pink colour appears at the end point.

\section{Peroxide value}

Peroxide value (PV) is a measure of the peroxides contained in a sample of fat expressed as mill-equivalent of peroxide per $1000 \mathrm{~g}$ of the material. The peroxide value (PV) was determined as per the method of the IUPAC (2006).

\section{Saponification value}

Saponification value of the oil was determined using the AOAC, 2000 official Method No. 920.160. It involved the preparation of $0.1 \mathrm{~N} \mathrm{KOH}$ solution with $95 \%$ ethanol and distilled. Oil sample was taken and weighed $5 \mathrm{~g}$ in a conical flask, the flask was fixed to an air condenser and oil was boiled until it was completely saponified. It was then cooled and titrated with $0.5 \mathrm{M}$ $\mathrm{HCl}$. Phenolphthalein acted as an indicator.

\section{Fourier transform infrared microscopy (FTIR)}

FTIR was performed in three different sets as mentioned below :

For the pure oil samples of soybean and sesame oil.

For the blend of both the soybean and sesame oil.

After the frying.

The FTIR was performed by Bruker's Alpha FTIR and the software used was OPUS.

\section{RESULTS AND DISCUSSION}

\section{Refractive index}

Refractive indices of oils are directly related to the number of double bonds in the oil i.e., more the number of double bonds, higher is the refractive index of the oil. However, relation with temperature is the opposite i.e., the refractive indices of oil decreased with increased in temperature. Moreover, oxidation of oil affects its refractive index. Refractive index of all the blends (Table 1) was 73 before frying. However, it increased slightly after frying. Data showed that there is not much change in the refractive indices of blends after repetitive frying. Consistent values showed that the oil blend is stable. However, in a study of soybean and cottonseed oil blends, it was reported that specific gravity of blends decreases due to the reduction of mass of oil and hence density as temperature increases (Prathibha et al., 2018).

\section{Viscosity}

Viscosity is a significant property of oil; it plays an important role in analysing the stability and quality of a food system. Viscosity represents the shear resistance. Results (Table 1) showed that the viscosity of all the blends and pure oils increased gradually over the frying cycles. Abdulkarim et al. (2007) reported that this viscosity increment was due to the polymerisation and formation of high molecular weight compounds. From the data given in Table 1, unfried oils had viscosity values ranging from 40.6 to 43.2 centipose $(\mathrm{Cp})$. The fried oils, according to their viscosity values, can be arranged in the decreasing order as $40 \%$ soybean oil: $60 \%$ sesame seed oil $>50 \%$ soybean oil: $50 \%$ sesame seed oil $>60 \%$ soybean oil: $40 \%$ sesame seed oil. After the first frying cycle, viscosity of blend $B$ decreased from 40.6 to 29 and that of blend $C$ decreased from 42 to 32.6. Prabsangob and Benjakul (2018) reported similar pattern in soybean and tes seed oil blend during frying and this could be because temperature rise leads to reduced intermolecular forces such that the layer of liquid easily passes over one another, resulting in a reduction in viscosity. However, viscosity values increased after second frying and subsequently after third frying cycle to 71.4 and 67.6 in case of blend $B$ and $C$, respectively. Hoffman et al. (2018) reported that during deep fat frying, polyunsaturated fatty acids hy- 
Table 1. Different parameters salues for Soybean oil, sesame seed oil and their blends.

\begin{tabular}{|c|c|c|c|c|c|}
\hline \multirow[t]{2}{*}{ Oil/Parameter } & \multirow{2}{*}{$\begin{array}{l}\text { Refractive } \\
\text { Index }\end{array}$} & \multicolumn{3}{|c|}{ Viscosity (Cp) } & \multirow[t]{2}{*}{ Specific Gravity } \\
\hline & & RPM 30 & RPM 50 & RPM 60 & \\
\hline$A$ & 73 & $43.2 \pm 0.91$ & $41.2 \pm 0.77$ & $41 \pm 0.67$ & 0.9056 \\
\hline$B$ & 73 & $40.6 \pm .46$ & $42.2 \pm 0.64$ & $42.2 \pm 0.00$ & 0.91 \\
\hline C & 73 & $42 \pm 0.50$ & $43.8 \pm 0.50$ & $43.7 \pm 0.34$ & 0.9048 \\
\hline A (1 $1^{\text {st }}$ frying) & 73 & $44.2 \pm 0.71$ & $44.1 \pm 0.75$ & $44.7 \pm 0.0 .40$ & 0.9056 \\
\hline A ( $2^{\text {nd }}$ frying $)$ & 74 & $46.2 \pm 0.05$ & $46.7 \pm 0.1$ & $46.7 \pm 0.11$ & 0.9296 \\
\hline$A\left(3^{\text {rd }}\right.$ frying $)$ & 75 & $73.4 \pm 0.87$ & $73.6 \pm 0.9$ & $73.5 \pm 1.00$ & 0.9372 \\
\hline$B\left(1^{\text {st }}\right.$ frying $)$ & 71 & $29 \pm 0.21$ & $29.6 \pm 0.50$ & $29.5 \pm 0.30$ & 0.8956 \\
\hline$B\left(2^{\text {nd }}\right.$ frying $)$ & 74 & $39.2 \pm 0.55$ & $39.6 \pm 0.40$ & $39.9 \pm 0.36$ & 1.0242 \\
\hline$B\left(3^{\text {rd }}\right.$ frying $)$ & 75 & $71.4 \pm 0.79$ & $71.8 \pm 0.88$ & $71.6 \pm 0.75$ & 1.0288 \\
\hline C (1 $1^{\text {st }}$ frying $)$ & 74 & $32.6 \pm 0.24$ & $33 \pm 0.00$ & $33.1 \pm 0.11$ & 0.892 \\
\hline$C\left(2^{\text {nd }}\right.$ frying $)$ & 74 & $43.2 \pm 0.19$ & $43.1 \pm 0.00$ & $43 \pm 0.20$ & 1.009 \\
\hline$C\left(3^{\text {rd }}\right.$ frying $)$ & 74 & $67.6 \pm 0.65$ & $68.2 \pm 0.50$ & $68.3 \pm 0.21$ & 1.0105 \\
\hline
\end{tabular}

Values are taken in triplicates and expressed as Mean \pm SE; Abbreviations: Sample A $=40 \%$ Soyabean oil \& $60 \%$ Sesame oil; Sample B $=60 \%$ Soyabean oil \& $40 \%$ Sesame oil; Sample C $=50 \%$ Soyabean oil \& 50\% Sesame oil; RPM = revolution per minute.

drolyse to form different compounds of high molecular weight. It can also be noted from the present results that as the proportion of sesame seed oil increased in the blend, it resulted in subsequent increase in the viscosity values.

\section{Specific gravity}

Specific gravity tells us how much heavy a substance is when compared to that of water. It does not have any units (Alireza et al., 2010). The specific gravity of oil increased as oil was repeatedly used for frying (Fig. 1). Blend $B$ has a specific gravity value of 0.91 , which increased to 1.0242 when the used oil was a second time used for frying. Further, after using the same oil for the third time, the specific gravity value rose to 1.0288 . Similar changes were observed in case of Blend $A$ and C. This rise could be due to formation of free fatty acids of different molecular weights. Similar results were reported in cottonseed and soybean oil blends during the study conducted in Telangana State Agricultural University, Hyderabad, India (Pratibha et al., 2018).

\section{Free fatty acid}

Fats hydrolyse to form free fatty acids and glycerol molecules. Free fatty acid (FFA) content indicates the extent of oil deterioration. There was an increase in the Percentage FFA content as oil is repeatedly used for frying (Fig. 2). Blend B (Soybean oil: sesame seed oil in the ratio 60:40) showed higher Percentage free fatty acid change $(27 \%)$ than the other two blends due to high unsaturation in soybean oil. Moreover, we noticed that there was less increase in FFA in Blend A (10\%) than Blend $C(13 \%)$. This can be attributed to the unsaturation present in soybean oil. Free fatty acids are a good indicator of hydrolytic rancidity for frying fats and oils, and as the cycles increase the content, FFA also enhances (Khanna and Chopra, 2020).

\section{Acid value}

The Acid value (AV) of the Blend $A$ after first frying is 1.6. It increased after second frying to 1.76. Similar observations were noted for Blend $B$ and $C$. Acid value of the Blend $B$ after first frying is 1.2 which rose to 1.36 after second frying and further to 1.52 after third frying. This could be due to formation of free fatty acids by hydrolysis of fat and oils. The increase in acid value for blend $A(10 \%)$ was lower than blend $B(13 \%)$ and blend C $(13 \%)$ which showed a greater increase in the acid value. Blend $\mathrm{C}$ contain higher amount of sesame seed

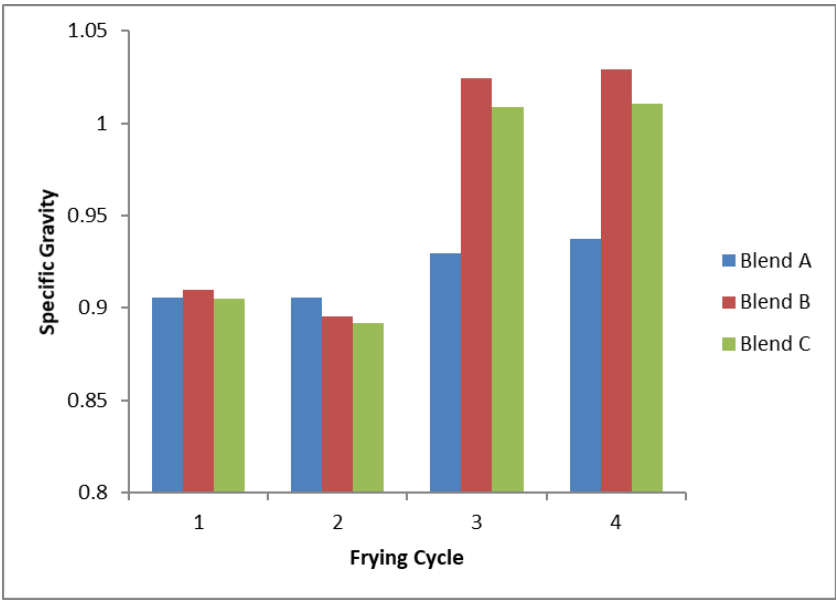

Fig. 1. Changes in specific gravity for blends of SBO and SSO as affected by various frying cycles. The numbers in $x$-axis 1,2,3 and 4 represents fresh oil samples, first frying, second frying and third frying, respectively. Abbreviations: Sample $A=40 \%$ Soyabean oil \& $60 \%$ Sesame oil; Sample $B=60 \%$ Soyabean oil \& 40\% Sesame oil; Sample $C=$ $50 \%$ Soyabean oil \& $50 \%$ Sesame oil. 


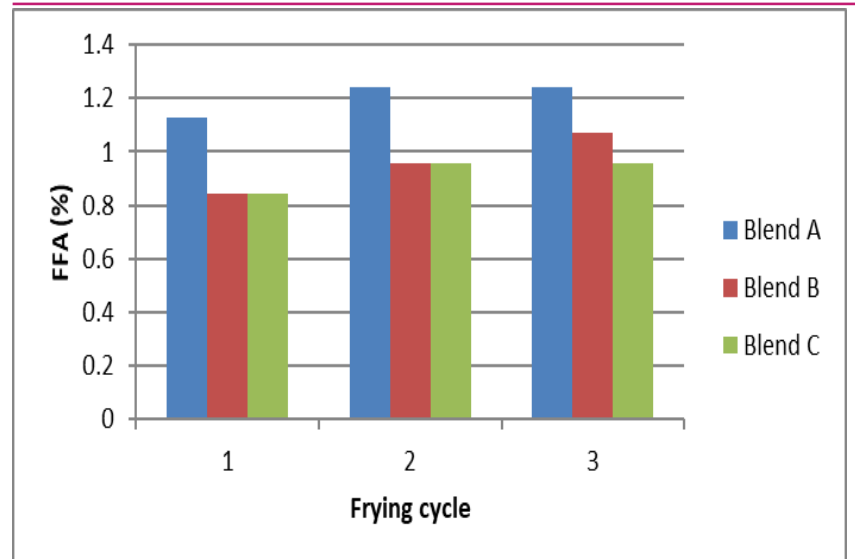

Fig 2. Changes in free fatty acid of SBO, SSO and their blends at different volume ratios as affected by various frying cycles. The numbers in $x$-axis 1,2, and 3 represents fresh oil samples, first frying, second frying and third frying respectively. Abbreviations: Sample $A=40 \%$ Soyabean oil \& $60 \%$ Sesame oil; Sample $B=60 \%$ Soyabean oil \& $40 \%$ Sesame oil; Sample $C=50 \%$ Soyabean oil \& $50 \%$ Sesame oil.

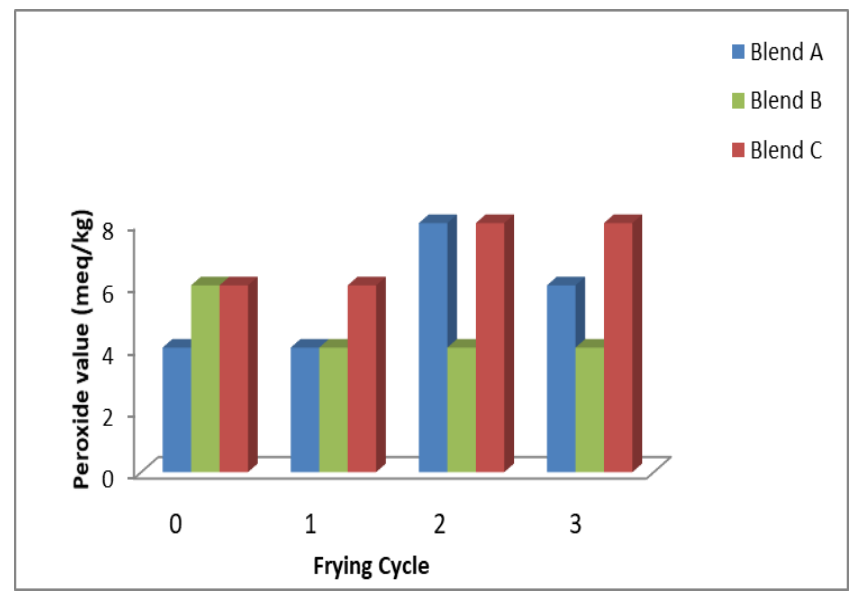

Fig 4. Changes in peroxide value of SBO and SSO blends at different volume ratios as affected by various frying cycles. The numbers in $x$-axis 1,2, and 3 represents fresh oil samples, first frying, second frying and third frying, respectively. Abbreviations: Sample $A=40 \%$ Soyabean oil \& $60 \%$ Sesame oil; Sample B $=60 \%$ Soyabean oil \& 40\% Sesame oil; Sample C $=50 \%$ Soyabean oil \& 50\% Sesame oil.

oil and thus lower increase in acid value in Blend $C$ indicates that sesame seed oil contributes to oxidative stability. Rodríguez and colleagues also reported that blending of sesame oil imparts oxidative stability to PUFA rich chia seed oil (Rodríguez et al., 2020). This could be because sesame oil contains less polyunsaturated fatty acids and antioxidants such as sesamol contribute to oxidative stability (Jayaraj et al.,2020).

\section{Peroxide value}

Lipids get oxidised to hydroperoxides in fats and oils, which lead to their deterioration. Thus, the determina-

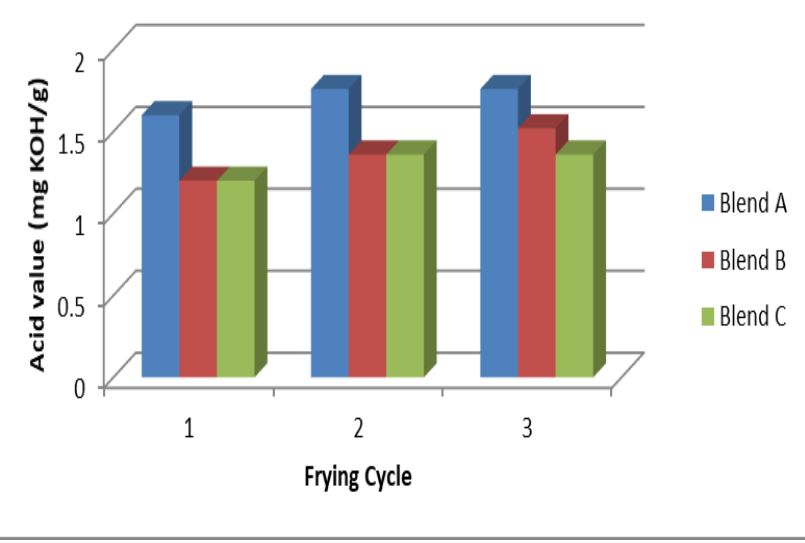

Fig. 3. Changes in acid value of SBO, SSO and their blends at different volume ratios as affected by various frying cycles. The numbers in $x$-axis 1,2, and 3 represent fresh oil samples, first frying, second frying and third frying, respectively. Abbreviations: Sample $A=40 \%$ Soyabean oil \& $60 \%$ Sesame oil; Sample $B=60 \%$ Soyabean oil \& 40\% Sesame oil; Sample C $=50 \%$ Soyabean oil \& $50 \%$ Sesame oil .

tion of Peroxide value (PV) is used as oxidative index for the early stages (Primary oxidation) of lipid oxidation in frying applications. The blend of soybean oil and sesame seed oil in the ratio of 40:60 had the least Peroxide value than the other two blends. However, peroxide value of oil increased when it was used for frying for the second time and further increased when used for the third time except for sample B. Some researchers reported that after some time during frying PV started to decrease due to the formation of secondary oxidation products. Changes in the PV are an important characteristic of oil that can be used to judge its quality and shelf life. It can often be used to monitor the potential shelf-life and is a good guide to the quality of fat (Ramadan and Wahdan, 2012). Similar results of increment of peroxide value due to frying reported by Arslan et al. (2016). But the values are less than 10 meq O2/ $\mathrm{kg}$, and, therefore, within the acceptable value range for fresh vegetable oils, according to the Codex Alimentarius Commission (2007).

\section{Saponificatio value}

$\mathrm{SV}$ of Blend A ranges from 62.832 to $88.638 \mathrm{mg} \mathrm{KOH} / \mathrm{g}$ of oil, while blend $B$ ranges from 85.272 to 97.614 and blend $C$ ranges from 79.662 to 109.956 . SV indicates the molecular weight of triglycerides in oil. The higher the saponification value (SV), the shorter is the average chain length. After first frying, the highest SV was found in blend B ( $60 \%$ soybean: $40 \%$ sesame seed oil), i.e., 85.272, while the lowest SV was found in Blend C, i.e., 79.662. With each frying cycle, we note from table2 that Saponification values keep on increasing. The shortening of the chain length can explain this due to hydrolysis, which resulted in increasing SV (Zahir et al., 2017). 


\section{FTIR}

FTIR studies have been conducted on the pure oils and sample number $A, B$ and $C$ to understand the chemical changes that have occurred in the structure of the oils on heating. Fig. 5 and 6 show the FTIR graph of the pure oils Soyabean and Sesame Oils, respectively. The structures of the soyabean and sesame oils are shown in Fig. 7 and 8, respectively for comparison purposes.

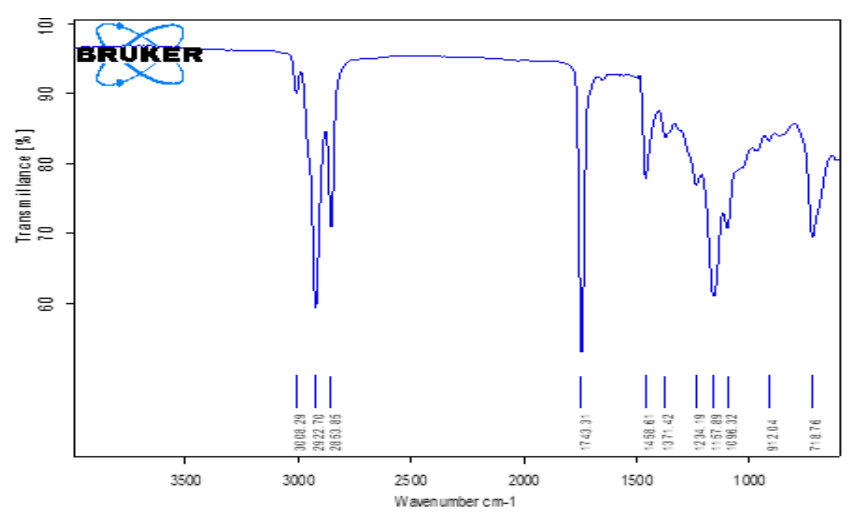

Fig. 5. FTIR of pure soybean oil.

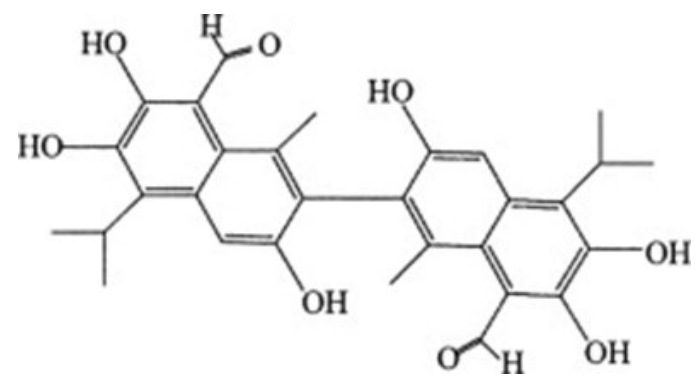

Fig. 7. Structure of sesame oil.

show the presence of all the characteristic peaks present in both the oils in Fig. 5 and 6. The sesame and soybean oil have relatively comparable FTIR results because almost all the functional groups present were same. FTIR data in Fig. 5 and 6 show the degradation products in the oil samples. The FTIR curves are shown below :

For the pure oil samples

For the blend of both the soybean and sesame oil.

FTIR curves of the sample A, B and C after frying for 3 Heating cycle are shown in Fig.9. When compared with the FTIR curves of the samples A, B and C (Fig. 10) without heating, the peaks appeared in Sample $A, B$ and $C$ and that of $A, B$ and $C$ after heating cycles are similar

Thus it can be concluded that heating the oils have not changed the chemical structure of any of the samples. All three samples ( $A, B$ and $C$ ) having different ratios of soybean and sesame oil show all the characteristic peaks of both the oils. The intensities of the peaks i.e., the amount of transmittance, in each curve have varied depending on the concentrations of each oil in the mix-
In Table 4, the FTIR peaks obtained and the corresponding functional groups present in the pure oils and their blends (Sample A, B and C) are summarized.

FTIR results confirm the presence of various bonds (C$\mathrm{C}, \mathrm{C}-\mathrm{O}, \mathrm{C}-\mathrm{O}-\mathrm{C}$, phenyl ring) in the pure oils, which match well with the oil structure. Sample A, B and C, which are mixtures of both the oils at (Soyabean oil: Sesame oil) 40:60, 60:40 and 50:50 ratio respectively,

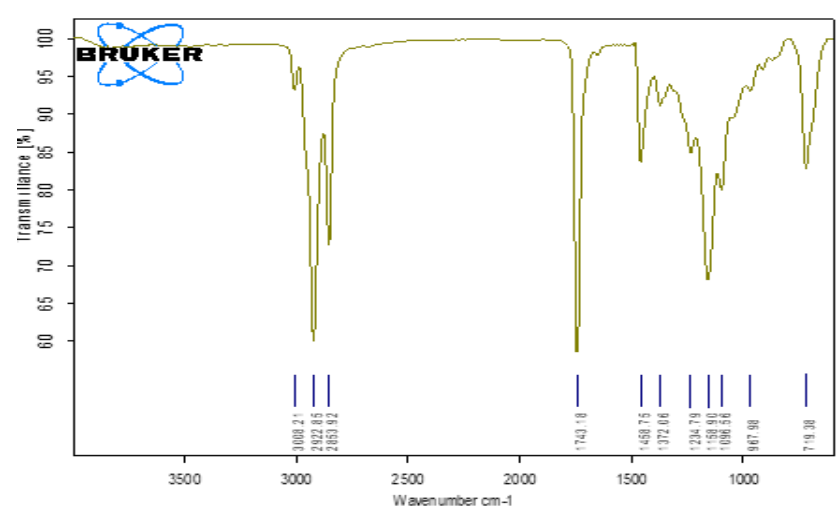

Fig. 6. FTIR of pure sesame oil.

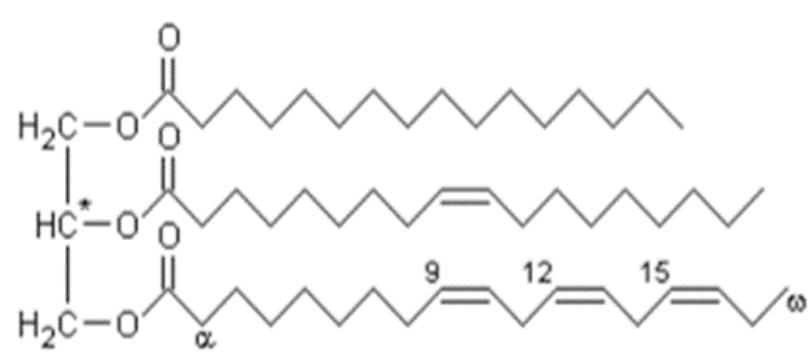

Fig. 8. Structure of soyabean oil.

Table 2. Saponification values $(\mathrm{mg} \mathrm{KOH} / \mathrm{g})$ of soybean and sesame oil blends for different frying cycle.

\begin{tabular}{ll}
\hline Oil/Parameter & Saponification Values* ${ }^{*}(\mathbf{m g ~ K O H} / \mathbf{g})$ \\
\hline FA1 & $62.83 \pm 0.75$ \\
FA2 & $80.78 \pm 1.20$ \\
FA3 & $88.63 \pm 1.82$ \\
FB1 & $85.272 \pm 1.71$ \\
FB2 & $90.88 \pm 2.70$ \\
FB3 & $97.61 \pm 2.13$ \\
FC1 & $79.66 \pm 0.58$ \\
FC2 & $88.63 \pm 0.69$ \\
FC3 & $109.95 \pm 1.56$ \\
\hline
\end{tabular}

*Values are taken in triplicates and expressed as Mean \pm SE Abbreviations: FA1: first day of frying of sample A; FA2: second day of frying of sample $A$; FA3: third day of frying of sample $A$; FB1: first day of frying of sample B; FB2: second day of frying of sample B; FB3: third day of frying of sample B; FC1: first day of frying of sample $C ;$ FC2: second day of frying of sample $C ; F C 3$ : third day of frying of sample $C$ 


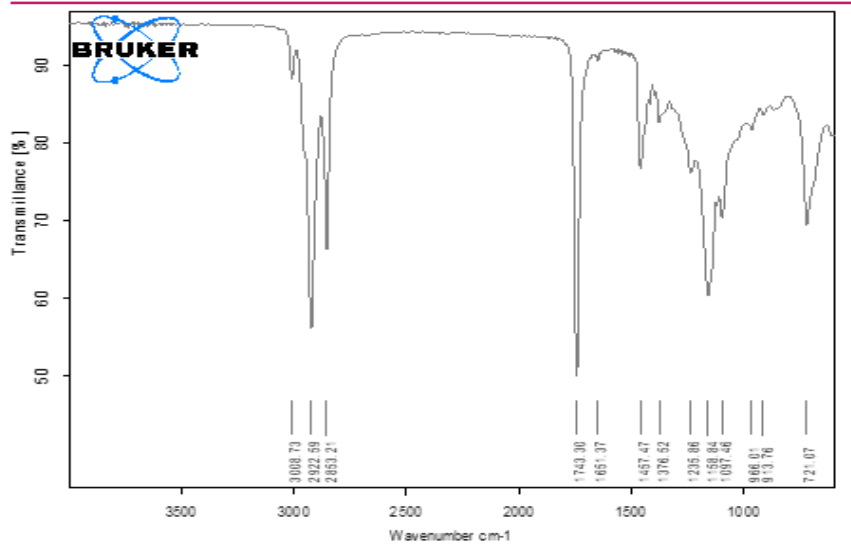

A

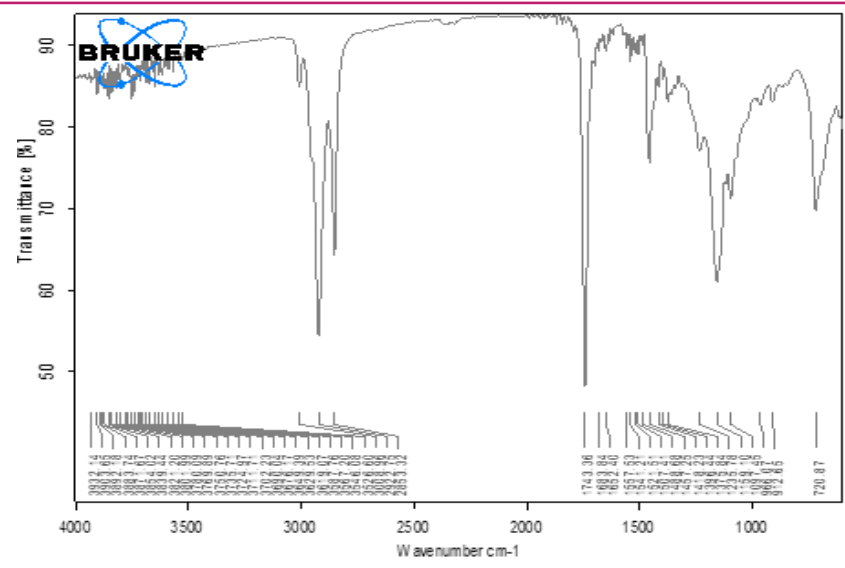

B

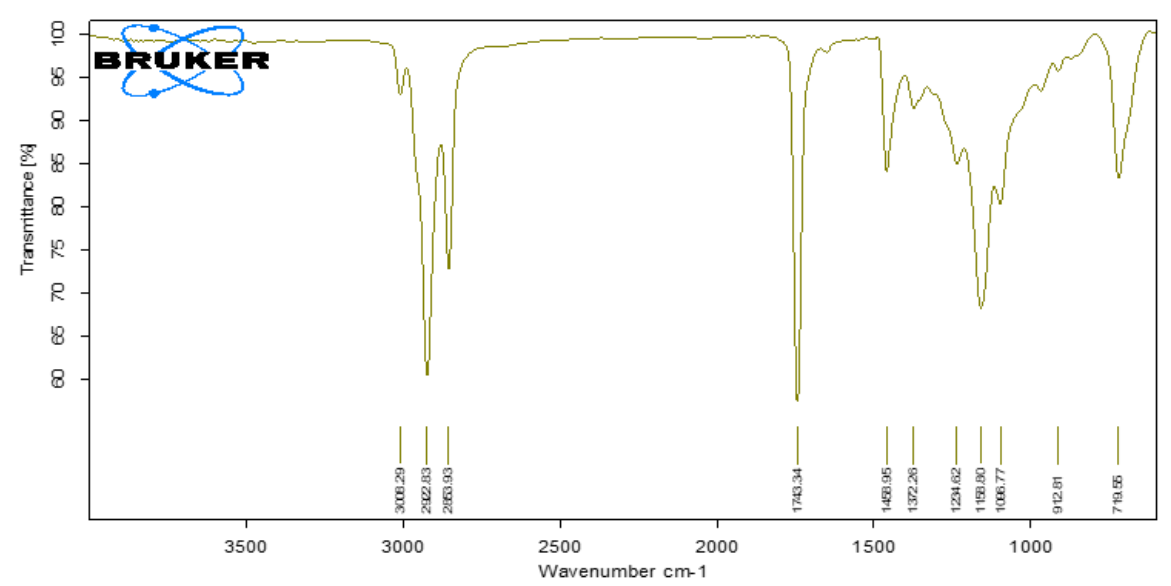

C

Fig. 9. FTIR of fried oils of (A) Sample A (B) Sample B and (C) Sample C. Sample $A=40 \%$ Soyabean oil \& $60 \%$ Sesame oil; Sample $B=60 \%$ Soyabean oil \& 40\% Sesame oil; Sample $C=50 \%$ Soyabean oil \& $50 \%$ Sesame oil.

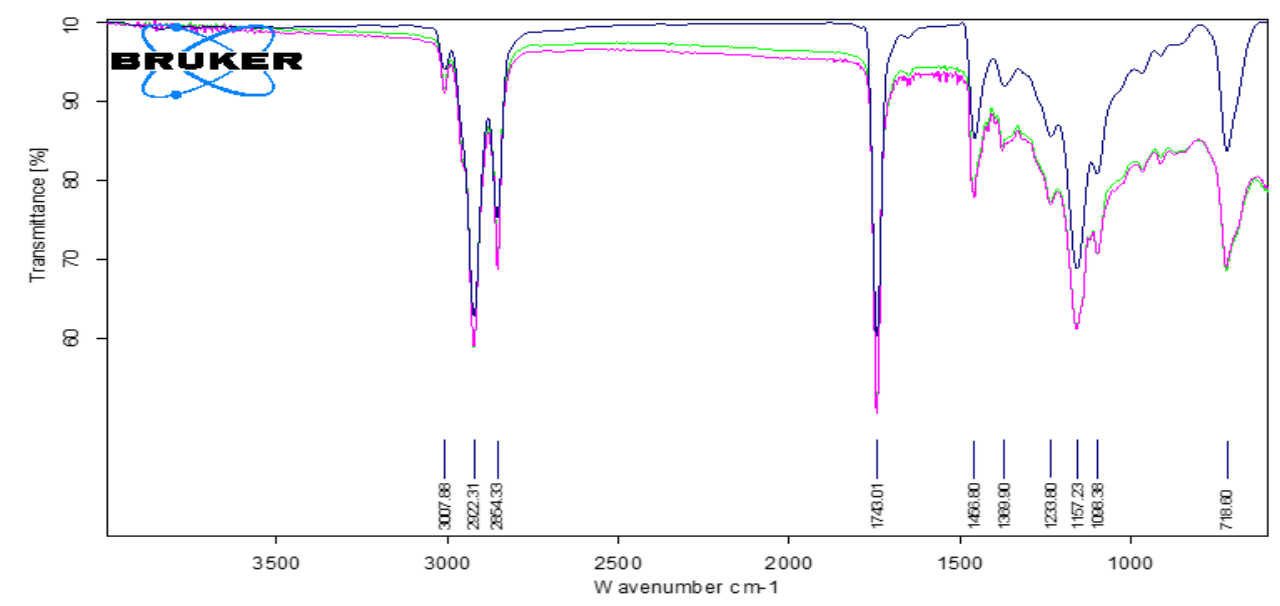

Fig. 10. FTIR of sample no. A (Soyabean:sesame 40:60), B(Soyabean:sesame 60:40), and C (Soyabean:sesame 50:50) without heating cycles. BLUE indicates sample A (40\% Soyabean oil \& $60 \%$ Sesame oil); PINK indicates sample B (60\% Soyabean oil \& 40\% Sesame oil ); GREEN indicates sample C (50\% Soyabean oil \& $50 \%$ Sesame oil)

Table 3. Comparison of the concentration of unsaturations in the two oils.

\begin{tabular}{llll}
\hline Oil & Saturated fats (\%) & Monounsaturated fats(\%) & Polyunsaturated fats(\%) \\
\hline Soybean & 16.0 & 23.0 & 58.0 \\
Sesame & 14.2 & 39.7 & 41.7 \\
\hline
\end{tabular}


Table 4. FTIR peaks and the functional groups present in soybean oil, sesame oil and their blends.

\begin{tabular}{|c|c|c|c|c|c|c|}
\hline $\begin{array}{l}\text { Peak position } \\
\left(\mathrm{cm}^{-1}\right)\end{array}$ & Functional group present & $\begin{array}{l}\text { Sample A } \\
(60: 40)\end{array}$ & $\begin{array}{l}\text { Sample B } \\
(40: 60)\end{array}$ & $\begin{array}{l}\text { Sample C } \\
(50: 50)\end{array}$ & $\begin{array}{l}\text { Soyabean } \\
\text { Oil }\end{array}$ & $\begin{array}{l}\text { Seesame } \\
\text { Oil }\end{array}$ \\
\hline 3007 & $\begin{array}{l}\text { olefinic } \mathrm{C} \mathrm{H} \text { stretching due to } \\
\text { unsaturated fatty raw materials. }\end{array}$ & Yes & Yes & Yes & Yes & Yes \\
\hline 2933 & aliphatic $\mathrm{C} \mathrm{H}$ stretching band & Yes & Yes & Yes & Yes & Yes \\
\hline 2854 & aliphatic $\mathrm{C} \mathrm{H}$ stretching band & Yes & Yes & Yes & Yes & Yes \\
\hline 1743 & $\mathrm{C} O$ stretching band & Yes & Yes & Yes & Yes & Yes \\
\hline 1456 & $\mathrm{C} \mathrm{H}$ bending vibration & Yes & Yes & Yes & Yes & Yes \\
\hline 1233 & C O C stretching vibration & Yes & Yes & Yes & Yes & Yes \\
\hline 1157 & $\mathrm{C}-\mathrm{O}$ bending vibration & Yes & Yes & Yes & Yes & Yes \\
\hline 1098 & & Yes & Yes & Yes & Yes & Yes \\
\hline 718 & methylene rocking vibration & Yes & Yes & Yes & Yes & Yes \\
\hline
\end{tabular}

(Source: Chiplinkar and Pratap, 2016); Abbreviations: Sample A= 40\% Soyabean oil \& $60 \%$ Sesame oil; Sample B $=60 \%$ Soyabean al \& $40 \%$ Sesame oil; Sample C $=50 \%$ Soyabean oil \& $50 \%$ Sesame oil

ture. Since the characteristic FTIR peaks of the pure oils are very similar to each other, the peaks in the FTIR curve of the blends have actually overlapped with each other and hence their intensities in the mixtures have also not varied much. However, the green line depicting sample $C$ with 50:50 ratio of both the oils is lying in between the blue and pink lines where the ratios of the oils are (soyabean: sesame oil) 60:40 and $40: 60$, respectively. Thus the results suggest that as the concentration of Soyabean oil increases, the absorption increases. The pink line shown by the pink line has $60 \%$ of sesame oil and $40 \%$ soybean oil and has the highest value of absorption and vice-versa (Fig. 10 ).

\section{Conclusion}

The effect of frying conditions on physicochemical properties of soybean and sesame oil blends (40:60, $60: 40,50: 50 \mathrm{v} / \mathrm{v}$ ) indicated that blending soybean oil with sesame seed oil improved its thermal stability since sesame seed oil contained large amounts of antioxidants such as sesamin, sesamol and tocopherol. Oil blend thus can bring a good opportunity for us to take advantage of desirable physico-chemical properties of the oil. It was also observed that blended oils took less time to reach the frying temperature, i.e. high heat transfer property. It was possibly an economically viable solution in the fried food industry. Therefore, by blending two oils in different proportions, a range of viscosities and heat transfer coefficients can be successfully achieved. Thus, the blending of soybean oil with sesame oil improved their frying performance. Further animal and human studies could also be performed to evaluate their impact on human nutrition.

\section{ACKNOWLEDGEMENTS}

The authors wish to express their profound gratitude to the Head and Teaching Faculty of Food Technology Department in the Bhaskaracharya college of Applied science, Delhi University, India, for their support during data collection.

\section{Conflict of interest}

The authors declare that they have no conflict of interest.

\section{REFERENCES}

1. Abdulkarim, S. M., Long, K., Lai, O. M., Muhammad, S. K. S. \& Ghazali, H. M. (2007). Frying quality and stability of high-oleic Moringa oleifera seed oil in comparison with other vegetable oils. Food Chemistry, 105(4),1382-1389.

2. Abdulkarim, S. M., Myat, M. W., Ghazali, H. M., Roselina, K. \& Abbas, K. A. (2010).Sensory and physicochemical qualities of palm olein and sesame seed oil blends during frying of banana chips. Journal of Agricultural Science, 2 (4), 18.

3. Abdulkarim, S.M. \& Ghazali, H. M. (2012). Fatty acid ratios and their relative amounts as indicators of oil stability and extent of oil deterioration during frying. J. Food Agri. Environ., 10, 33 -38.

4. Abou-Gharbia, H. A., Shehata, A. A. Y. \& Shahidi, F. (2000). Effect of processing on oxidative stability and lipid classes of sesame oil. Food research international, 33(5), 331-340. https://doi.org/10.1016/S0963-9969(00)00052-1

5. Aidos, I., Lourenclo, S., Van der Padt, A., Luten, J. B. \& Boom, R. M. (2002). Stability of crude herring oil produced from fresh by products: influence of temperature duringstorage. Journal of Food Science, 67(9), 33143320.http://dx.doi.org/10.1111/j.1365-2621.2002.tb0 $9585 . \mathrm{x}$ 
6. Alireza, S., Tan, C. P., Hamed, M. \& Che Man, Y. B. (2010). Effect of frying process on fatty acid composition and iodine value of selected vegetable oils and their blends. International Food Research Journal, 17(2), 295302.

7. AOAC (2000).Association of Official Analytical Chemists (AOAC). Official methods of analysis. In: William $\mathrm{H}$, editor. Oils \& fats. Gaithersburg, MD, USA, 2, 295-302.

8. AOCS (2000). Sampling \& analysis of commercial fats \& oils. AOCS official method USA: AOCS Cold Spring Harbour.

9. Arslan, F. N., Şapçı, A. N., Duru, F. \& Kara, H. (2017). A study on monitoring of frying performance and oxidative stability of cottonseed and palm oil blends in comparison with originaloils. International Journal of Food Properties, 20(3), 704-717. https://doi.org/10.1080/10942912.20 16.1177544.

10. Boskou, D.,Tsimidou, M. \& Blekas, D. (2006). Polar phenolic compounds, In: Olive Oil, Chemistry and Technology, D. Boskou, (Ed.), pp. 73-92, AOCS Press, ISBN 978-1 -893997-88-2, Champaign, IL, USA

11. Chiplunkar, P. P. \& Pratap, A. P. (2016). Utilization of sunflower acid oil for synthesis of alkyd resin. Progress in Organic Coatings, 93, 61-67. https://doi.org/10.1016/j.po rgcoat.2016.01.002

12. Cocks, L. V. \& Van Rede, C. (1997). Laboratory Handbook for Oil and Fat Analysis Academic Press London.

13. Codex Alimentarius Commission (2007). Report of the twentieth session of the Codex Committee on fats and oils. Joint FAO/WHO Food Standards Programme, $30^{\text {th }}$ session, London, UK

14. Debnath, S., Rastogi, N. K., Krishna, A. G. \& Lokesh, B. R. (2009). Oil partitioning between surface and structure of deep-fat fried potato slices: A kinetic study. LWT-Food Science and Technology, 42(6), 1054-1058. https://doi.or g/10.1016/j.lwt.2009.01.006.

15. Dhyani, A., Chopra, R. \& Garg, M. (2018) A Review on Blending of Oils and Their Functional and Nutritional Benefits. Chem. Sci. Rev. Lett., 7(27), 840-847.

16. Farhoosh, R. \& Esmaeilzadeh Kenari, R. (2009). Anti rancidity effects of sesame and rice bran oils on canola oil during deep frying. Journal of the American Oil Chemists' Society, 86(6), 539-544. https://doi.org/10.1007/s11746009-1382-7

17. Hashempour-Baltork, F., Torbati M, Azadmard-Damirchi S, Savage GP. (2016). Vegetable oil blending:A review of physicochemical, nutritional and health effects. Trends in Food Science \& Technology, 57, 52-58. https://doi.org/1 0.1016/j.tifs.2016.09.007

18. Hoffmann, J. F., Vaitilingom, G., Henry, J. F., Chirtoc, M., Olives, R., Goetz, V. \& Py, X. (2018). Temperature dependence of thermophysical and rheological properties of seven vegetable oils in view of their use as heat transfer fluids in concentrated solar plants. Solar Energy Materials and Solar Cells, 178, 129-138.https://doi.org/10.10 16/ j.solmat.2017.12.037

19. International Union of Pure and Applied Chemistry (IUPAC) 2006. Standard Methods for the Analysis of Oils, Fats and Derivatives, 1st Supplement to the 7th Revised and Enlarged Ed., Blackwell Scientific Publications, Oxford.

20. Jayaraj, P., Narasimhulu, C. A., Rajagopalan, S., Par- thasarathy, S. \& Desikan, R. (2020). Sesamol: A powerful functional food ingredient from sesame oil forcardioprotection. Food \& function, 11(2), 1198-1210.

21. Khanna,P. \& Chopra, R. (2020). Oxidative and thermal stability of linseed oil blend and its application as frying oil. Annals, Food science and Technology, 21(4), 680-690.

22. Kumar, P. P., Bhatnagar, A. S., Hemavathy, J. \& Krishna, A. G. (2009). Changes in physico-chemical characteristics of some vegetable oils upon blending with coconut oil. $J$ Lipid Sci Technol, 41(4), 136-142.

23. Kochhar, S. P. (2002). Sesame, Rice bran and flax seed oil. Vegetable oils in Food Technology. Composition, Properties and Uses. Gunstone, F. D (Eds.), SRC Press LLC, pp. 297-322.

24. Latif, S. \& Anwar, F. (2011). Aqueous enzymatic sesame oil and protein extraction. Food Chemistry, 125(2), 679684. https://doi.org/10.1016/j.foodchem.2010.09.064.

25. Li, Y., Ma, W.J., Qi, B.K., Rokayya, S., Li, D., Wang, J., Feng, H.X., Sui, X.N. \& Jiang, L.Z., (2014). Blending of soybean oil with selected vegetable oils: impact on oxidative stability and radical scavenging activity. Asian pacific Journal of Cancer Prevention, 15(6), 2583-2589. https:// doi.org/10.7314/APJCP.2014.15.6.2583

26. Man, Y. C. \& Tan, C. P. (2002). Comparative differential scanning calorimetric analysis of vegetable oils: II. Effects of cooling rate variation. Phytochemical Analysis, 13(3), 142-151. https://doi.org/10.1002/pca.634

27. Mokbli, S., Sbihi, H., Nehdi, I., Romdhani-Younes, M., Tan, C. \& Al-Resayes, S. (2018). Characteristics of Chamaerops humilis L. var. humilis seed oil and study of the oxidative stability by blending with soybean oil. J. Food Sci. Technol., 55(6), 2170-2179. https://doi.or g/10.1007/s13 197-018-3134-x

28. Pandurangan, M. K., Murugesan, S. \& Gajivaradhan, P. (2014). Physico-chemical properties of groundnut oil and their blends with other vegetable oils. Journal of Chemical and Pharmaceutical Research, 6(8), 60-66.

29. Prabsangob, N., \& Benjakul, S. (2019). Effect of tea catechin derivatives on stability of soybean oil/tea seed oil blend and oxidative stability of fried fish crackers during storage. Food science and biotechnology, 28(3), 679-689. https://doi.org/10.1007/s10068-018-0515-x

30. Prathibha,S., ReddyV.S., Suneetha W J, Kumari B. A, Lakshmi V.V and Maheswari, K.U. (2018). Physicochemical, Functional and Sensory Properties of Vegetable Oil Blends. Current Journal of Applied Science and Technology, 29(4), 1-11.

31. Ramadan, M. F. \& Wahdan, K. M. M. (2012). Blending of corn oil with black cumin (Nigella sativa) and coriander (Coriandrum sativum) seed oils: Impact on functionality, stability and radical scavenging activity. Food Chemistry, 132(2), 873-879. https://doi.org/10.1016/j.foodche m.2011.11.054

32. Rangkadilok, N., Pholphana, N., Mahidol, C., Wongyai, W., Saengsooksree, K., Nookabkaew, S., \& Satayavivad, J. (2010). Variation of sesamin, sesamolin and tocopherols in sesame (Sesamum indicum L.) seeds and oil products in Thailand. Food Chemistry, 122(3), 724-730. https:// doi.org/10.1016/j.foodchem.2010.03.044

33. Rodríguez, G., Villanueva, E., Cortez, D., Sanchez, E., Aguirre, E. \& Hidalgo, A. (2020). Oxidative stability of Chia (Salvia hispanica L.) and Sesame (Sesamum indicum L.) 
Garg, M. et al. / J. Appl. \& Nat. Sci. 13(3), 820 - 829 (2021)

Oil Blends. Journal of the American Oil Chemists' Society, 97(7), 729-735https://doi.org/10.1002/aocs.12357

34. Sankar, D., Pugalendi, K.V., Sambandam, G., Rao, M.R. (2003). Sesame oil helps reduce dose of blood pressure lowering medicine. Meeting report. 4/28/200; from<http:// www. American heart.org/presenter.

35. Toliwal, S.D., Tiwari, M.R. \& Verma, S. (2005). Studies on thermal stability of palm-corn oil blends. Journal of Oil Technology Association of India, 37, 18-20.

36. Zahir, E., Saeed, R., Hameed, M. A., \& Yousuf, A. (2017). Study of physicochemical properties of edible oil and evaluation of frying oil quality by Fourier Transform Infrared (FT-IR) Spectroscopy. Arabian Journal of Chemistry, 10, S3870-S3876. https://doi.org/10.1016/j.arabjc.2014.05.0 25 